\title{
Screen Interface Design for Mobile-assisted Language Learning in EFL Context: A Case Study in Japan
}

\author{
Ruth Patricia Cortez \\ School of Computer Science and Engineering, University of Aizu, Japan \\ Email: rpatycr@gmail.com \\ Debopriyo Roy \\ Center for Language Research, University of Aizu, Japan \\ Email: droy@u-aizu.ac.jp
}

\begin{abstract}
Mobile Technology is constantly evolving and offering new capabilities for supporting higher data transmission, storage, and multimedia formats that can be beneficial for Language Acquisition. Mobile Assisted Language Learning (MALL) publications have been reviewed for two main perspectives: The Content -based approach and the Design- issues approach. This study focuses on understanding these approaches and identifying their main challenges specific to MALL activities. Mobile-based e-learning applications and learning possibilities are tied to the physical attributes of the device, graphical user interface, and the cost of services, collaboration tools, Internet access, and computation capabilities. This article reports extensively on the results of a focus group-oriented study undertaken using an IPod- based English learning application for five advanced (graduate) EFL (English as foreign language)-based students in a Japanese technical university. Results from this pilot analysis were reported towards exploring the design of the IPod interface and how it contributes towards mobile assisted language learning. Results indicate that students are mostly comfortable using handheld devices and completed tasks with reasonable success and efficiency. However, they faltered with few steps mainly due to complexity of the screen interface (lack of on-screen guidance), transition within and between steps, and unresponsive system. The qualitative analysis focused mostly on the design of the graphical user interface, its delivery methods, and user preference and information access patterns. Several recommendations are made for both the design of the interface and how content should be structured.
\end{abstract}

Index Terms - mobile-assisted language learning, education, IPod, interface design, content approach

\section{INTRODUCTION}

Today elearning is envisioned as a feasible option, as well as a unique opportunity to reduce educational costs and use teaching resources more efficiently (Ruth, 2010). Added to e-learning, the increasing use of mobile technologies and wireless communication is opening a new field of research where the main focus becomes the use of mobile devices in education, also known as mobile learning (m-Learning). This strategy is seen as the next step of the eLearning paradigm and will extend the meaning and dimension of "Anytime, Anywhere" education (Song, 2008). Mobile assisted language learning (MALL) is relatively new in Japan and there is still much research to be done about the scope of its design and application. However, research has already shown its tremendous potential in a tech-savvy country like Japan. Naismith et al. (2004) refer to the fact that a web-based Japanese system for English language learning - Pocket Eijiro - receives more than 100000 hits per day. This system was designed for access via WAPenabled mobile phones.

One such mobile assisted language-learning device is the IPod. In Kukulska-Hulme and Traxler's (2005) study of mobile learning, iPods were used to aid language learning, wherein they function as digital voice recorders or camcorders to produce interviews and make audiovisual presentations. Chinnery (2006) briefly mentions iPods in the context of a new area that he names MALL or: Mobile Assisted Language Learning, an outgrowth of the more established Computer Assisted Language Learning or CALL. In this study, we will try to explore the importance of IPod for language learning a little differently. The primary purpose of this study is to explore the extent to which the IPod touch screen interface could be designed successfully towards language learning and/or acquisition, and deliver content in a way that supports EFL (English as foreign language) learning contexts. What are the units of focus (e.g., curriculum design, assessment mechanism, content delivery, content management, content and interface design etc) when designing such on-screen language-learning applications in IPods? Is the handheld-based language learning 
applications different in complexity, functionality, interactivity, adaptability, and accessibility (when compared to its desktop counterparts)? Overall, how are such applications designed?

\section{BACKGROUND MOTIVATION}

While many successful research projects have worked on developing rules to guide the design and implementation of interfaces for desktop machines and their applications, the design of mobile device interfaces is still relatively unexplored and unproven (Gorienko and Merrick, 2003; Tarasewich et al., 2007). With numerous design challenges that are yet to be explored and solved for hand held applications, the problem is certainly compounded when nonnative users of English use mobile devices as a language learning platform. This article is an open exploration, trying to explore the world of mobile assisted language learning and the interface design issues that promotes or impairs the process of understanding hand held devices as a platform for language acquisition. While in-class observations have adequately demonstrated the multiple uses of mobile devices and portable dictionaries for word search, translation, meanings etc, it is not entirely clear the extent to which users might find it reasonable to use their handheld devices for self-paced language acquisition. With limited motivation and time for English language study in a Japanese context, it is obvious that the efficacy of the user interface might play a big role in making the user feel welcome and comfortable in the world of mobile assisted language learning.

\section{FoCUS AND SigNIFICANCE}

This study is significant because it explores the usability of IPod screen interface as a language-learning medium. It makes an attempt to understand how users perform through different learning modules, where they succeed and falter, how they navigate, what motivates and frustrates them and their overall reaction to the task.

Major Research Question: As there is not much previous research on this topic, the major research question examined here is the extent to which relatively advanced EFL learners in Japan with reasonable experience in handheld devices like mobile phones and IPod might follow along and complete short tasks using an IPod-based English interface.

The primary research question addressed in this study is:

a) When using a latest generation mobile device, such as the iPod touch, what issues related to device interaction are challenges in a Japanese EFL context?

The answer to the major research question will also shed some light on the following questions.

- What aspects of the user interface can facilitate the learning activity?

- Using an application that follows the principles of the design issues approach, what aspects of pedagogy benefit or constrains the learning activity?

\section{LITERATURE REVIEW}

MALL is an approach to language learning that is enhanced through the use of a mobile device (Keiman and Aizawa, 2004). In general, the most common devices considered for MALL are cell phones, MP3/MP4 players, PDA's and smart phones (Thornton and Houser, 2004). The "mobility" dimension of the approach is what makes these devices attractive for learning, as they can extend the paradigm to "anytime, anywhere". Another important dimension towards its efficient functioning and acceptability is its user interface design. Ben Shneiderman provides a complete, current, and authoritative introduction to user-interface design. The user interface is the part of every computer system that determines how people control and operate that system. When the interface is well designed, it is comprehensible, predictable, and controllable; users feel competent, satisfied, and responsible for their actions (Shneiderman \& Plaisant, 2009).

MALL Design Approaches

Research (Kukulska-Hulme and Shield, 2008) suggests that there are two main approaches utilized in the development of MALL activities. These categories relate to formal and informal structures for mobile content access and are a possible indicator that suggests how the content and interface should be designed.

Content -based approach: This approach focuses on content delivery. The most frequent delivery method uses mobile phones and is text-based, through text messaging or email and quizzes and surveys for vocabulary teaching (Ruth, 2010). Another example is the use of MP3 players like iPods for audio content in assignments.

Design- issue approach: This approach is related to informal (anytime and anyplace) learning activities specifically for mobile devices, where learners have more flexibility in choosing content, time, and work-flow. Informal learning might be equally rich in content, but the difference is rather in the way the content is accessed by the student.

The activities are fragmented as small tasks, designed to be completed within short time frames (Song, 2008). Research (Morita, 2003) suggests that flexibility of use is more oriented to making use of spare time rather than being restricted only to classroom activities. Moreover, the strategy does not assume any previous preparation in order to 
perform the learning. Research (Ghazvini et al., 2009) provides several examples of cell-phone games, and SMS as part of the informal learning strategies. In the first example, SMS and email are used to teach English to government employees. The second example is implemented as a mobile game for primary children for them to practice spelling and learn new vocabulary in the Farsi language. The third example is a mobile game used to teach technical English vocabulary to university students in computer science.

The initial point of any web-based course design is to analyze the precise learning needs, the target learners and then formulate a course objective, before selecting the most suitable design approach (Horton, 2000).

With the content -based approach, the aim of the activities is to have more formal learning or classroom-based activities, similar to instructor-led activities. The objectives can be defined as, but not limited to, preparation, reinforcement, and evaluation. The preparation activities can include the design and delivery of new content integrated into the class. Reinforcement activities take into consideration the materials reviewed in class and stimulate content retention; an example is vocabulary review, through SMS/MMS, language practice via video/audio, etc. The evaluation activities should measure the effectiveness of the learning through quizzes and exercises.

The intent of the design-issues approach is to create self-paced, asynchronous and, therefore, more learner-led activities. There are four factors that need consideration for both approaches during course design. These include the following:

a) Mobility. Innovative activities should be oriented to take advantage of the mobility aspect as suggested in (Kukulska-Hulme, 2009). According to Kukulska-Hulme (2009) study, the use of mobiles should enrich the learning process and bring forth new possibilities that cannot be achieved through traditional and stationary means.

b) Collaboration. It is important to be able to differentiate between activities that are designed around collaborative versus those designed around individual activities. For example, collaborative versus simpler quiz activities (group vs. individual) could be considered and planned accordingly.

c) Re-Usability. It is important to select content formats that are compatible with different mobile platforms due to the existing diversity of devices to avoid restricting learner options.

d) Connectivity. This factor relates to course access. During the design, how the activity will be accessed by the learner is important and should be identified. For example, the activities might need to be completed online, meaning that constant Internet access is required, either through $3 \mathrm{G}$ or Wi-Fi. Another consideration might be to allow users to download content or certain features of a course to work offline and then submit once Internet access is available.

\section{Addressing Key Learner Considerations}

According to Horton (2000), ideal learners should have the following specific characteristics: "a) learns independently and views learning positively; b) Self-disciplined, manages time well, enjoys working alone; c) Able to express [oneself] clearly in written [format]; d) Have basic computer skills and value the role of technology in business and learning; e) Need to acquire new knowledge, but cannot easily attend traditional training." Most of these characteristics apply to mobile courses with the exception of $(\mathrm{d}$,) where it is not only necessary to have computer skills because the mobile activity is similar to a typical online course, but also, because it is key to be familiar with the mobile devices and services required to complete the actual learning activity.

Also, interface adaptability to learning styles is important. Each learner has different preferences and needs. Therefore, it is very crucial to provide the different styles of learners with different learning environments that are more preferred and more efficient to them (Cha et al., 2006; Wolf, 2003).

Moreover, it is also important to understand the kind of learner the reader is, and adopt the screen task accordingly. However, few existing systems have the ability to adapt to student or user's learning style (Paredes and Rodriguez, 2002). Currently, many researchers agree on the importance of modeling and using leaning styles, however there is little agreement in aspects of learning style are worth modeling, and what can be done differently for users with different styles (Brusilovsky, 2001). Moreover, the relationships between leaning styles and possible interface settings are still an unclear area (Brusilovsky, 2001).

\section{User Interface Design: Designing the GUI Interface}

Interface design is one of the most important aspects of mobile design. There are five main User Interface Design principles: User familiarity, Consistency, Minimal Surprise, Recoverability, and User Guidance (Sommerville, 1995). To explain the different types of possible interaction for mobile applications, we used the guidelines for iPhone development, which utilizes a comprehensible approach to user-centered design (Apple developer, see reference).

There are three user interface factors that must be considered during the content and structure design of a mobile course:

a) Include only the essential task. Considering the compact size of the mobile device, this design should only include the elements that are essential to the task; otherwise the interface can be confusing for the user.

b) Have sequential access. Tasks should be designed sequentially, so the user can see only a single screen at a time. This is one of the main differences between a handheld and a PC User interface. A task can be divided into a sequence of screens when that task requires several steps. 
c) Providing minimal on-screen help. Mobile users tend to spend less time using an application than PC users do. Hence, an interface should be as intuitive as possible and follow a clear and logical flow to complete the task. This factor strongly relates back to the principles of user familiarity, consistency and minimal surprise.

In any mobile course, the user will interact with the learning material through direct manipulation of on-screen objects instead of using an intermediate object like a mouse. Therefore, there is an advantage when engaging the learners in the task, because there is more control of the activity, and better understanding of the action result. As an example, for iPhone application interfaces, user interactions are described with metaphors (Apple developer, see reference) that represent actions like 1) Tapping controls, 2) Dragging, flicking, or swiping objects in a game, 3) Sliding On/Off switches, 4) Flicking through pages of photos, and 5) Spinning picker wheels to make choices.

\section{How does MALL Support EFL-based Training?}

Mobile technology is currently a feasible approach for overcoming many of the obstacles found in the current methods of EFL reading instruction. Mobile- assisted language learning (MALL) has the capability to provide an EFL learner with the same opportunities for independent and targeted reading practice and immediate corrective feedback as does CALL (Lan et al, 2007). In recent years, various studies have explored new methods of language learning actually made possible by the unique features of MALL, including portability, social interactivity, context sensitivity, connectivity, individuality, and immediacy [Attewell \& Webster (2004); Chinnery (2006); Klopfer et al., (2002); Soloway et al., (2001)]. Recently, Poodle, a mobile-based course management system, was designed to facilitate the deployment of educational materials to mobile phones. This application supports ubiquitous polls, quizzes, wikis, forums, and flash cards (Houser and Thornton, 2005).

The same study in Japan (Houser and Thornton, 2005) has shown that $71 \%$ of the subjects preferred receiving their English lessons (vocabulary) on mobile phones rather than on their PCs. Of this group, 93\% felt this deployment to be a valuable teaching method. In the study, thirty-one Japanese college sophomores evaluated the site, using videocapable mobile phones, found few technical difficulties, and rate its educational effectiveness highly. Another study (Thornton and Houser, 2004) demonstrated the importance of mobile applications for language training in Japan. The research (Thornton and Houser, 2004) presents three projects in mobile learning. They polled 333 Japanese university students regarding their use of mobile devices and 100\% reported owning a mobile phone, $99 \%$ sent email on their mobile phones, exchanging some 200-email messages each week.

Using IPods for Educational Purposes

Since the release of the first iPod in 2001, the device has developed many educational uses. Part of the attraction of the iPod as an educational device is the fact that it contains easily accessible audio and visual content in an attractive and conveniently sized package. Recent iPod models have become progressively more versatile, and the availability of their educational content is growing exponentially. Universities across the United States have also recognized the value of the iPod as an educational tool for college students and have begun issuing free iPods to incoming freshmen (Read, 2005). Duke University became one of the first higher education institutions to distribute iPods to freshmen in 2004 (Dean, 2004).

Several questions regarding iPod educational applicability remain unanswered and that is what this article attempts to do within its restricted scope. How do we know exactly what a user finds to be user-friendly, how do users navigate, what kind of errors do students commit, how do students search and retrieve information for mobile applications, what are the overall design issues (icons, layout of the site, colors, etc)? How do these issues both help and impede the mobile-assisted language learning process?

\section{RESEARCh METHODOLOGY}

One of the most important conditions to reach the successful design of a product is the early participation of potential users of that system. This section describes an exploratory MALL-based design analysis in a focus group that reported on the end-user interaction with an IPod, designed to complete a specific set of MALL-based language learning activities through self-paced modules. The testing focused on task workflow, interaction with the application and the device, the experience of the user, the learning outcome, and the learning style (Winckler et al., 2007 edited).

Reasons for deciding on a focus group analysis: Focus groups are effective ways to explore new research ideas, explore a topic that is difficult to observe, collect concentrated data over a short period of time, and gather solid preliminary data [Catterall and Maclaran (1997); Asbury (1995)].

\section{Procedure}

As part of this focus-group analysis, a scenario-based evaluation method was followed. Through observing the descriptions of scenarios, everyone had an equal opportunity to propose his/her suggestions and criticisms to discover the real needs of users, a critical step to draw out the final appearance of the system (Carroll, 2000).

The conversational English learning module had multiple lessons from which to choose. During the observation segment, participants were required to complete six of seven tasks for one particular lesson (No. 7), the same for all participants. They were instructed to follow a task order from $1-7$, except for Task 4 . They each followed the same 
sequence, and each lesson had a series of tasks. The chosen lesson was similar to other lessons in terms of user interface design, pattern of sequencing, and levels of difficulty (content complexity) within and between the tasks.

The usability study was performed through an observation of the task steps and the interviews. Each participant took around 45 minutes to complete the IPod application, and then answered the questions asked by the interviewer in detail. The interviewer noted each step/activity as each participant completed it. The notes mainly related to where the users tapped on the screen, their levels of comfort with the keypad, their levels of comfort with the audio/video output, and whether the instructions were followed adequately, whether the navigation was seamless, where transition from one step to another was obvious or confusing, and finally, any points where the participants needed help. As the participants interacted, they were asked to think aloud and respond to any specific queries that the interviewer had. Guidelines on performing the task were provided, and participants were allowed to take as much time as they needed to complete the tasks. They were also asked to follow the task sequence suggested by the application.

After completion of the tasks, the participants were interviewed and asked to answer a set of questions about their impressions of the activity. The interview was performed on the basis of a written survey questionnaire that acted as a reference for the interviewer. The interview covered five areas: Task workflow, interaction with the application and device, experience of the user, learning outcome, and learning style. A retrospective think-aloud protocol was also part of the interviewing session, whereby participants could re-visit the application, interact with it freely, and voice their opinions about the activity and the questions being asked by the interviewer. Figure 1 shows screenshots to explain how the participants proceeded from one task to the next. The screenshots are not necessarily in the order of access, but do provide an overall idea of the possible navigation patterns.
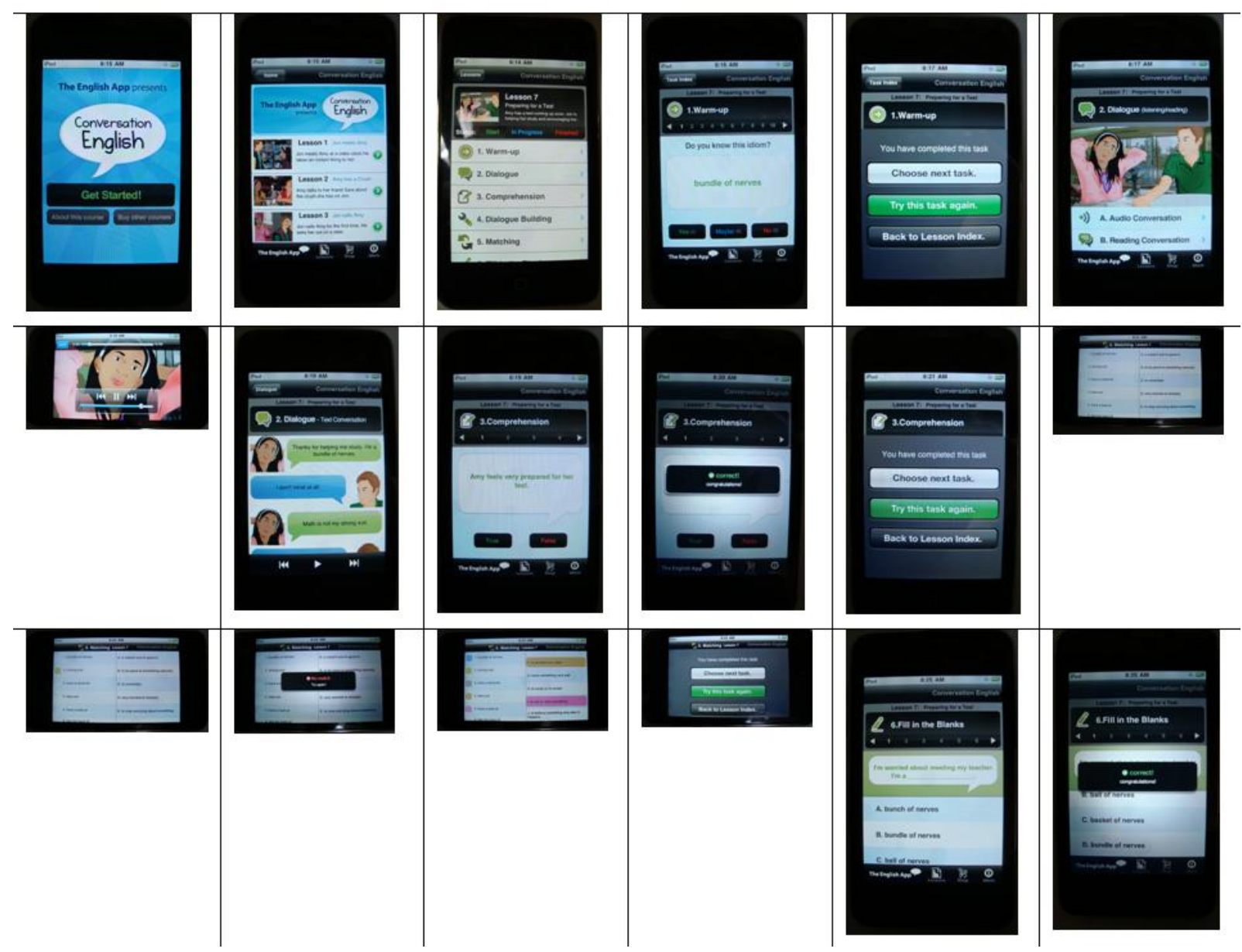

Fig1. Screenshots showing how the lessons were interacted with and navigated by the participants

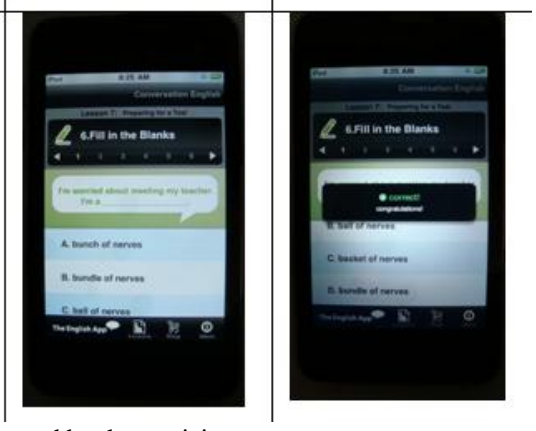

Figure 2 shows an example of the instructions in the interview on that questionnaire that each participant had to follow. 


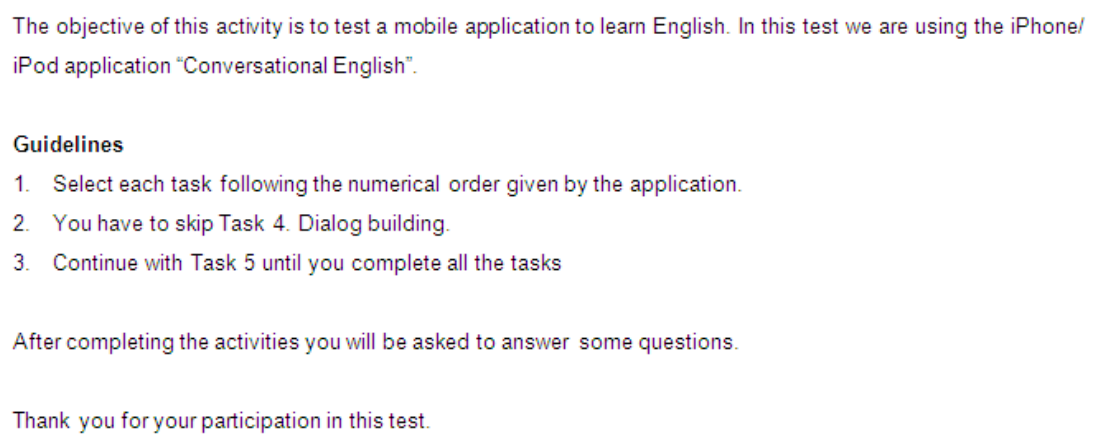

Fig2. Instructions Given to Participants

Figure 3 shows the different categories and related questions in the post-test survey. The survey was not handed out to the participants. Rather, the questions acted as a guideline for the interviewer to ask questions to the participants and elicit more specific answers with clarifications, wherever necessary.

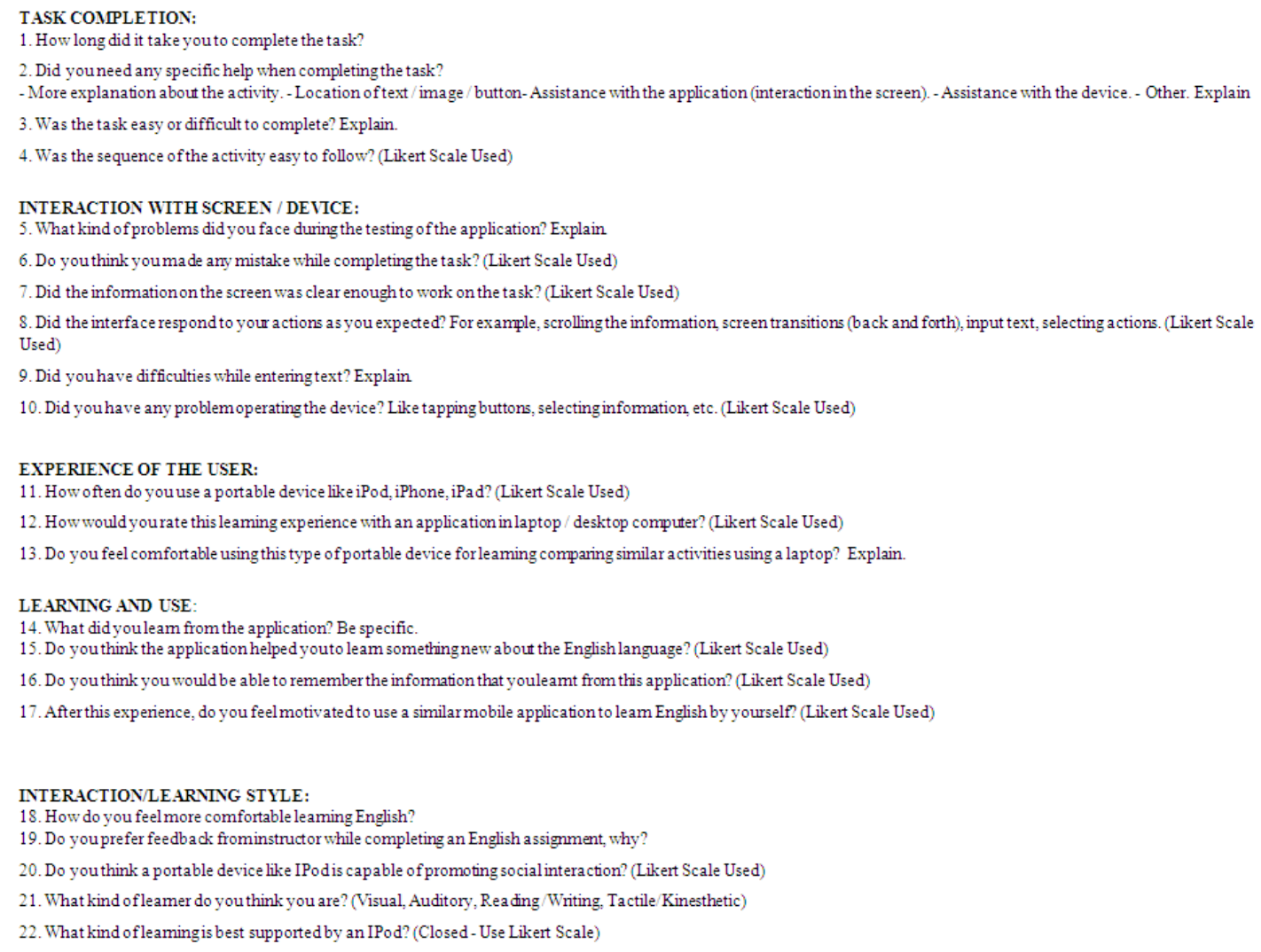

Fig3. The different categories and related questions in the post-test survey

It is important to mention in this context that the items and questions used for the post-test interview was based more on the standard guidelines and items used for any usability interview session, and for analyzing most user interfaces. However, in the current scenario the following reference articles and books (Horton, 2000; Nielson and Molich, 1990; Hackos and Redish, 1998) were used and the following relevant and important items were selectively used to understand how users completed the task.

Task Steps and Their Sequence: The following chart shows the sequence of steps that were followed by the participants (in most cases) when completing the task. 
TABLE 1:

STEPS SEQUENCE - OBSERVATIONS

\begin{tabular}{|c|c|c|}
\hline 1. & Select Warm-up activity. & Specific Observation (if any?) \\
\hline 2. & Answerif they know the idiom. (Yes/Maybe $\mathrm{No}$ ) & \\
\hline 3. & Tap on Choose next task. & \\
\hline 4. & Select Dialog. & \\
\hline & Select Audio conversation. & \\
\hline & Select Reading Conversation. & \\
\hline & Play the audio button andread, while listening to the conversation & \\
\hline 8. & Select the Dialog button. & \\
\hline & Select Task Index button & \\
\hline & Select Comprehension task. & \\
\hline & After each answer tap on message button & \\
\hline & Tap on Choose next task. & \\
\hline & Select Matching task & \\
\hline & Tap on left side list & \\
\hline & Tap on right side list & \\
\hline & Tap on message (Match No match) & \\
\hline & Tap on Choose next task & \\
\hline & Select Fill in the Blanks Task & \\
\hline & Scroll over the answers and Tap one & \\
\hline & Tap on message (Correct/Wrong). & \\
\hline & Tap on Choose next task & \\
\hline & Tap on View Lesson Idioms & \\
\hline 23. & Tap on the Arrow button of the idiom & \\
\hline & Tap on the sound icon & \\
\hline 25 . & Tap on button(Yes Maybe No) to acknowledge Idiom understanding & \\
\hline 26. & Tap on Next Idiom & \\
\hline & Select "Go to Lesson 7" after reviewing all the idioms. & \\
\hline
\end{tabular}

The observer noted down whether participants followed the sequence, how much time they spent with each step, and if there was any specific additional/remedial action undertaken (e.g., going back to a previous step, scrolling down, clicking patterns etc) when completing a step or transitioning from one step to the next. Table 1 shows the list of specific activities and their sequence.

\section{Test Instruments}

In this focus group design analysis, we were interested in a preliminary analysis that is generalizable across most MALL-based devices and for a large section of the EFL population.

Reasons for choosing the application:

a) The participants in the current study are those using English as foreign language with moderate knowledge of English. The purpose of the application is to improve the usage of Idioms in every day conversation, being suitable for the sample we will be testing.

b) The vocabulary acquisition is through language in context, by introducing the new idioms in a Dialog and a Dictionary with example phrases showing its usage.

c) The application follows Design issues approach, and lessons are well organized in short tasks that user has to complete to learn idioms vocabulary.

d) Other aspect considered is to have a variety of content delivery, such as video, audio, reading, and writing. The application incorporates all of these resources to make the learning more interactive.

e) The cost of the application is very accessible (600 yen).

f) "Conversation English" is an iPhone application, which is also compatible with iPod Touch being the device used for our experiment. The iPhone is a very popular device in Japan. Therefore, we started with the possibility that users will already be familiar with the application interface, thereby making experiment guidelines easier to follow.

g) Collaboration aspect is not included in the application. This feature could be later incorporated without much variation on the interface and the previous activities, as an additional module to practice the lesson materials. This is one of the challenges of the current applications. 
How the application follows the design issues and NOT the content-based approach? The aim of the design issues approach is to allow the user to learn through a self-paced set of activities. The activities should be designed to accomplish three main objectives: content acquisition, reinforcement and evaluation. The major activities for the application are as follows - Warm -up, Dialog, Comprehension, Dialogue Building, Matching, Fill in the blanks, View Lesson Idioms etc (20 lessons in total).

One of the aspects that characterize the Design Issues approach is that the activities are designed to make use of the users' spare time. Therefore, it doesn't require much preparation to complete the activities. The application is compliant with this principal. The tasks were designed with a suggested order, but the user can switch between them without losing the flow of the learning process, with exception of Task 2, which is content acquisition, because the reinforcement activities are based in the Dialog Task. The application allows for flexibility to adapt to user preferences for language acquisition. The user can decide whether to learn the idiom vocabulary in context by completing first the Dialog Task 2, or by moving to Task 7 and review the meaning. The Warm-up, gives an overview of the idioms that will be learned in the lesson, but it doesn't give information on the meaning. By completing this activity, the student can have a quick grasp of the new or already known idioms to be studied in the lesson.

The activities are designed to be completed during a short time frame, which is also another important aspect of focusing on spare time. The Dialog video lasts between 1-1:30 minutes, and the activities are designed to be completed in less than 5 minutes. The longest task is number 4, in which the time depends on user skills to remember the order of the conversation. The application also provides a way to remember which lessons the user has to complete by providing a status marker. (Green $=$ started, Blue $=$ in progress, Red $=$ Finalized). This feature is not available for keeping the status of the task within a lesson, which it could also be considered as an improvement point. Even though the lesson has been completed, the user can repeat as many times each of the tasks.

\section{The Participant Sample}

For this study, we obtained participants by personally contacting five volunteers to join a focus group. The study focused on Japanese students using English as a foreign language and having moderate English language ability in writing and reading comprehension. Fluency of spoken English was not a criterion for selection of the participants. These participants (advanced computer science students at graduate level) were observed separately during other inclass assignments to ensure that their variations in ability with respect to the following skills (mobile usage, IPod usage, ability to process English text, and listening) were within reasonable limits.

\section{RESULTS AND FINDINGS}

Overall, majority of participants could complete the task with reasonable efficiency. However, this section focuses on the specific issues during interaction, where they needed help, committed mistakes, the system failed to respond, and where the interaction was easy to handle.

\section{Interactions during the Task Completion Process}

Participant 1 had little experience with a similar device, but required guidance to clarify the task sequences; finally he completed $93 \%$ of the expected steps. He seemed to have difficulty interacting with the application, especially when he was trying to go back to menus or tapping buttons. During the Selection of Reading Conversation (Step 6), he tapped on the Lessons button and thus went back to the main menu by mistake. After completion of the activity, he tapped The English application button by mistake and had to reload the lesson to this point again (Step 9). During the Fill- in -the- Blanks task (Step 20) he tapped the Lessons button by mistake again and went back to the main menu twice. This mistake might have been caused by the Tab bar design for the application. While reviewing the idioms (Step 24), the participant tapped on the sound image, but the application closed and thus had to be reloaded up to the task again. During the next step for the same task (Step 25), the participant tried to confirm comprehension of only one Idiom. However, the application did not respond (even after multiple tapping), and thus it was skipped to access the rest of the Idioms.

Participant 2 had little experience with a similar device. He was able to complete $81 \%$ of the expected sequences. Most of the guidance provided was to help him locate the buttons on the screen. On the Warm- up activity, he had to confirm whether he knew the idiom (Step 2). Instead of answering that question directly, he jumped to the Idiom dictionary. After reviewing the Idiom, he moved to the English app information screen. Then he closed the application by mistake and had to reload it again (step 3). In the Dialog task, instead of selecting Reading conversation (step 6), he tapped the Idiom button and opened the Idiom dictionary by mistake. From this point forward, he had difficulties going back to the activity and needed help to select the right options to go back. After completing the listening part (Step 8), he required guidance to select the options to return to the lesson Task Menu. While taking the Idioms review, he did not try the sound icon or tap the confirmation buttons.

Participant 3 had no experience with a similar device, but she was able to complete $96 \%$ of the expected sequence, and required very little guidance. In the Dialog task (Step 7), she required some additional time to play the audio while reading the conversation. This requirement for additional time was also observed in the Comprehension task, 
where she needed additional time to figure out that it was necessary to tap on the message button (Step 11) to move forward. This behavior was similar on each new interaction she had with the application (Steps 14, 15) which was probably related to her lack of previous experience with a similar device. While completing the task, Fill in the Blanks, she tapped on the Shop button and had to reload the application (Step 20). At this point, she did need some guidance to use the device and go back to the application we were testing. During the last task, Idioms review (Step 24), the application closed when she tried listening to the sound and this step was skipped after the first trial. Similarly, she tapped the button to confirm Idiom understanding, but when she didn't receive any response from the application, she ignored it.

Participant 4 appeared to be (and even reported) as being very familiar with a similar device, the iPhone. She completed $89 \%$ of the expected steps. At the beginning of the activity, she needed additional information about the tasks to be performed and the sequence of those tasks. During selection of Reading conversation (Step 7) she didn't use the audio feature to listen to the dialog while reading the conversation. During the last task, Idioms review (step 24), she didn't try the sound, and this step was skipped after a first trial. Similarly, she tapped the button to confirm Idiom understanding, but since the system did not respond, it too was ignored (Step 25).

Participant 5 is familiar with a similar device, the iPhone. She completed $74 \%$ of the expected steps, and although the interaction was not a problem, she required more guidance on the task sequence and the English. During the Dialog task (Step 7), she took some time to play the conversation and read along with it. Also, she had some difficulties finding the button to go back to the dialog (Step 8), and so she asked for help to continue the activities. After the comprehension task, she chose a different option than expected to go back to the lesson main menu (Step 12). In the Matching activity, she also took some time to understand how the interaction worked (Step 15). For the task Idioms review, the audio option was skipped (Step 24), and she tried to acknowledge the understanding of the idiom, but since there was not a response from the application, this step was stopped (Step 25). In the same task, she experienced some difficulties in moving forward with the idioms. The following figures demonstrate the issues experienced during user interaction with the application. Figure 4 shows the percentage of accurate responses for each participant.

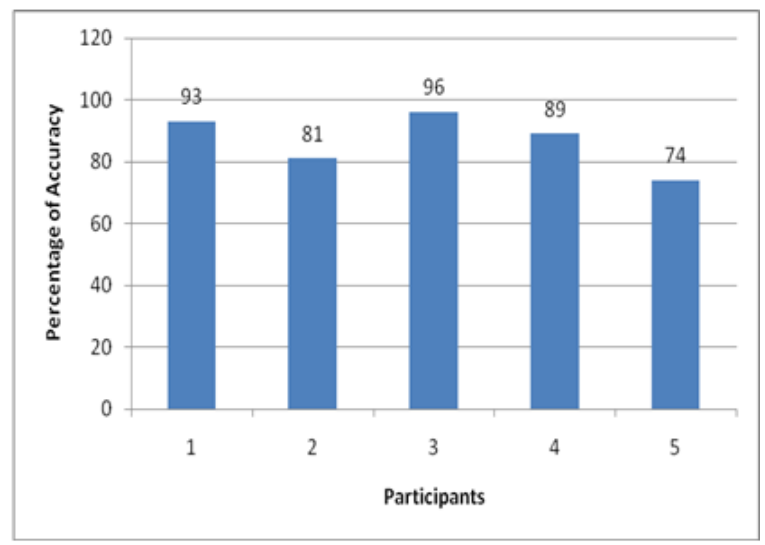

Fig4. Percentage of Accurate Responses

Figure 5 shows the frequency of mistakes committed by each participant during interaction with the on-screen application. Figure 6 explains the number of times the system did not respond during interaction. Figure 7 shows the frequency of difficulty and required guidance during on-screen interaction.

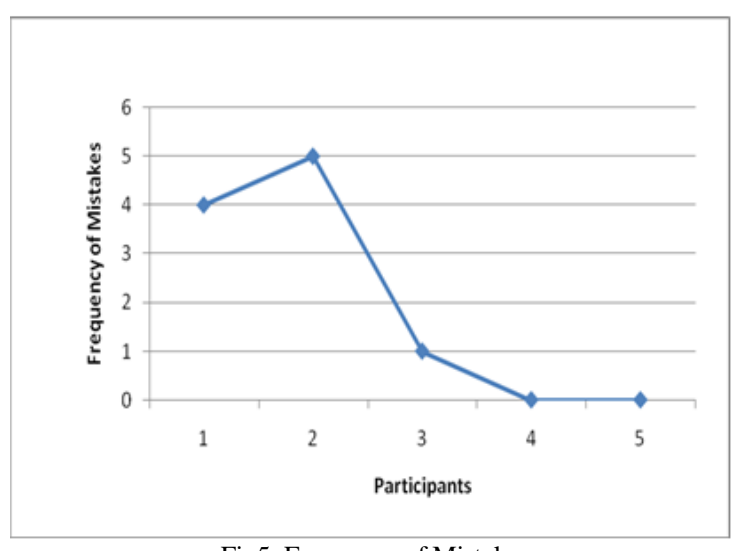

Fig5. Frequency of Mistakes 


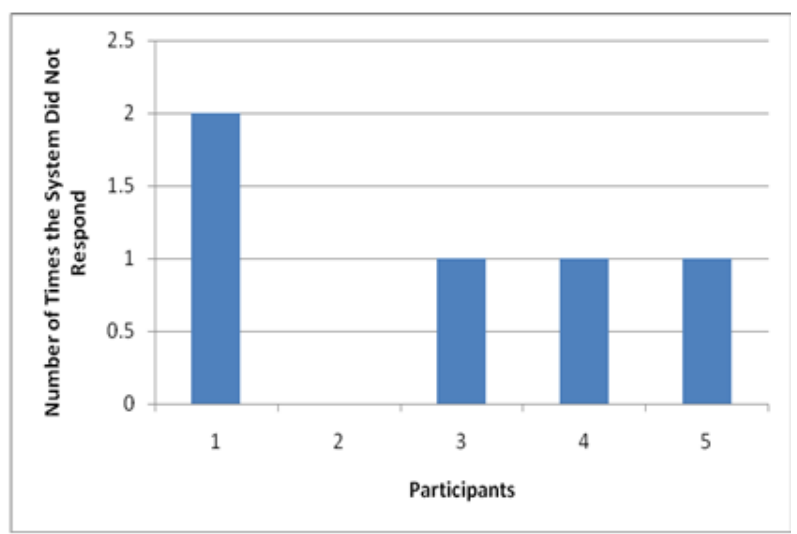

Fig6. Number of Times the System did not Respond

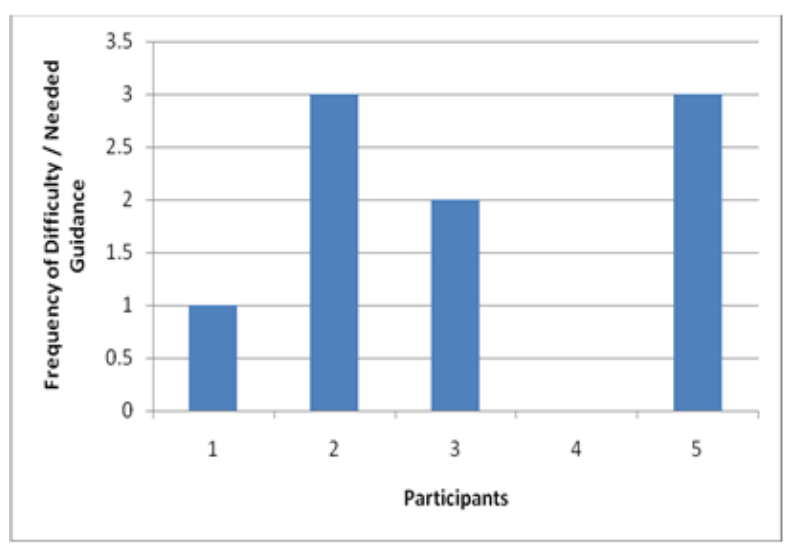

Fig7. Frequency of Difficulty and required guidance during on-screen interaction

Figure 8 provides an overview of the type of difficulties and guidance needed for specific actions.

\begin{tabular}{|l|l|}
\hline Participant & Difficulty / Guidance Required \\
\hline $\mathbf{1}$ & Going back to the main menu \\
\hline $\mathbf{2}$ & Help locating buttons on screen \\
\hline $\mathbf{2}$ & Select option to go back to the activity \\
\hline $\mathbf{3}$ & Select option to go back to lesson task menu \\
\hline $\mathbf{3}$ & Use of keypad \\
\hline $\mathbf{4}$ & Going back to the application \\
\hline $\mathbf{5}$ & None \\
\hline $\mathbf{5}$ & Guidance on task sequence \\
\hline $\mathbf{5}$ & Guidance on English content \\
\hline $\mathbf{5}$ & Finding the button to go back to the dialog \\
\hline
\end{tabular}

Fig8. Steps / activities where participants needed guidance and faced difficulties

Figure 9 demonstrates the steps where readers had trouble. 


\begin{tabular}{|l|l|}
\hline Participants & Steps \\
\hline 1 & $3,7,12,17,21,24,27$ \\
\hline 2 & $7,24,27$ \\
\hline 3 & $2,3,6,23,25$ \\
\hline 4 & 6,9 \\
\hline 5 & 27 \\
\hline
\end{tabular}

Fig9: Steps where readers faltered and /or had trouble

\section{Issues with the Application}

All the participants had difficulty completing Step 24 caused by an error in the application. After tapping the sound icon of the idiom, very often the application closed down and the application had to be reloaded. The buttons for the Tab bar were very small and it was easy to tap on them by mistake. During Step 25 of this task, the application displayed three buttons to confirm the understanding of the idiom and visually suggested that any one of the buttons could be tapped, but there was no response from the application or a summary to measure the comprehension percentage.

\section{Interview Findings}

After completing the task, the participants answered 22 questions about their learning experience while completing the MALL tasks. The interviewer used a survey response to question the participants and helped them answer the question, by clarifying the question and its scope. These findings are classified in five areas of discussion as described below.

Task Completion: The time taken to complete the task was between 20 to 25 minutes for $80 \%$ of the participants. Only one person took 10 minutes, but she had experience using an iPhone. All of the participants required additional help either to follow the task sequence or return to the task if by mistake the application was closed. Also, most reported that the task was easy to follow, but three found it difficult to understand the English. Some also pointed out that following the suggested sequence of the application allowed them to comprehend the idioms better. Figure 10 demonstrates self-reports on the ease with which the task was completed. Primarily, the self-report answers the extent to which the sequence of activity was easy or difficult to follow on a likert scale.

\begin{tabular}{|l|l|}
\hline Participant & Was the sequence of task easy to follow? \\
\hline 1 & Somewhat \\
\hline 2 & Somewhat \\
\hline 3 & Somewhat \\
\hline 4 & To a great extent \\
\hline 5 & Somewhat \\
\hline
\end{tabular}

Fig10. Task Completion

Interaction with the Screen and the Device: Interaction with the devices was mostly positive, except for situations when the system did not respond, sometimes even after repeated tapping. This unresponsive state, however, was not misconstrued as lack of their participant's ability to complete the task. They were perceived as issues with the application, or the participant not being familiar with the device. According to their ratings, the application provided enough information to indicate the task flow and responded to their actions as expected, in most cases, even though some of the participants were not very familiar with the device. These responses suggest that the intuitive nature of the IPod application helped with the sequence of activities. However, one participant thought the screen size was too small, especially for cases when he had to complete matching tasks (the answers were not clearly visible and not easy to pick out when presented in a list). Another participant pointed out that when a sequence was somehow missed and the main index revisited, the application was not intuitive enough to jump steps. Another participant pointed out that for people without experience using IPod apps, they should have the option of reading extra steps to understand where to tap, scroll, and transition between screens. Figure 11 identifies the issues related to the interaction with screen interface and what participants thought about the interaction. 


\begin{tabular}{|l|l|l|l|l|}
\hline Participant & $\begin{array}{l}\text { Mistake while } \\
\text { completing task? }\end{array}$ & $\begin{array}{l}\text { Information Clarity } \\
\text { on screen }\end{array}$ & $\begin{array}{l}\text { Did the interface } \\
\text { respond to action? }\end{array}$ & $\begin{array}{l}\text { Any problem operating the device? } \\
\text { Example: tapping buttons, selecting } \\
\text { information, etc. }\end{array}$ \\
\hline 1 & Very Little & Somewhat & Somewhat & Somewhat \\
\hline 2 & Somewhat & To a great extent & Somewhat & Very Little \\
\hline 3 & Very Little & To a great extent & Somewhat & Not at all \\
\hline 4 & Very Little & To a great extent & To a great extent & Not at all \\
\hline 5 & Somewhat & Very Little & Somewhat & Very Little \\
\hline
\end{tabular}

Fig11. Interaction with screen interface

Experience of the User: Three participants had some first-hand experience with a similar device, although they were not using it constantly and for the purpose, as evidenced during the testing session. One owned an iPhone, and the last one had no experience at all before the test. All had a positive impression of the learning experience with the mobile device. As reasons for that liking, they indicated the portability aspect, such as size, made it convenient for this type of activity. Another aspect that was suggested was their similarity with games they often played using their mobile devices, which they perceived as fun. Apparently, they found this interface similar. However, that did not necessarily mean there was any similarity in the nature and context of such use. Figure 12 identifies how users rated the experience with the IPod and handheld devices in general.

\begin{tabular}{|l|l|l|}
\hline Participant & $\begin{array}{l}\text { Experien oe of using handheld device for } \\
\text { learning purposes }\end{array}$ & $\begin{array}{l}\text { Compare handheld vs. Laptop } \\
\text { experience }\end{array}$ \\
\hline 1 & Seldom Desktop learning \\
\hline 2 & Never & Handheld experience was interesting \\
\hline 4 & Sometimes & Handheld experience was interesting \\
\hline 5 & Always & Handheld experience was interesting \\
\hline
\end{tabular}

Fig12. Experience of the user

Learning and Use: Most of the participants pointed out that they learned the English Idioms, as per the objective of the application, and also one participant stated that he could develop a new learning strategy for himself from the process and sequence that was guided by the application. All the participants agreed with a positive review that they were able to acquire new knowledge during the testing session and also were positive about the long- term retention of the Idioms in their memory and then applying them in conversations. Another participant said she liked practicing listening and pronunciation using native speakers. One participant stated he found it easier to learn the phrases in their context of use (as in sentences), rather than as isolated words with dictionary meanings only. The participants also were motivated to try a similar application again for their self-study. Figure 13 explained what participants responded about IPod usage for English language acquisition.

\begin{tabular}{|l|l|c|l|}
\hline Participant & $\begin{array}{l}\text { Did the application help leam } \\
\text { something new about English } \\
\text { language }\end{array}$ & $\begin{array}{l}\text { Would it be possible to } \\
\text { remember information leant in } \\
\text { this application? }\end{array}$ & $\begin{array}{l}\text { After this experience, I feel motivated to use } \\
\text { a similar mobile application to leam English } \\
\text { by myself. }\end{array}$ \\
\hline 1 & To a great extent & Somewhat & Agree \\
\hline 2 & To a great extent & To a great extent & Agree \\
\hline 3 & Somewhat & To a great extent & Agree \\
\hline 4 & To g great extent & To a great extent & Agree \\
\hline 5 & To a great extent & Somewhat & Agree \\
\hline
\end{tabular}

Fig13. Learning and use

Learning Style: One of the concerns for MALL is whether it is possible to promote collaboration among students. We were interested in getting a preliminary opinion from the participants based on their experience and personal learning styles. The majority of them stated they feel more comfortable having interaction with a group and yet retain the option to learn individually, depending on specific learning modules. Two indicated they feel more comfortable with individual learning. Four out of five participants mentioned that instructor feedback on the activities were important. The capability of a portable device as a means of social interaction, combined with MALL-based activity, was rated differently. For three, it was positive, considering that tools like chat can be made available, but might not be tied to any specific activity, and two participants stated that MALL-based devices might not be suitable for 
promoting such interaction. Regarding the learning styles, diverse opinion existed for all of them, but the majority identified as visual learners. The perception of a device that supported a particular learning style leaned toward the visual and auditory. Figure 14 identified the reader preference and learning styles of the user.

\begin{tabular}{|c|c|c|c|c|c|}
\hline Participant & $\begin{array}{l}\text { How do you prefer to leam } \\
\text { English? }\end{array}$ & $\begin{array}{l}\text { Do you prefer feedback } \\
\text { from instructor when } \\
\text { completing assignment? }\end{array}$ & $\begin{array}{l}\text { Is IPod capable of } \\
\text { promoting social } \\
\text { interaction? }\end{array}$ & $\begin{array}{l}\text { What kind of leamer are } \\
\text { you? }\end{array}$ & $\begin{array}{l}\text { What kind of leaming is } \\
\text { best supported by IPod? }\end{array}$ \\
\hline 1 & $\begin{array}{l}\text { Comfortable leaming English } \\
\text { individually as well as in a } \\
\text { group }\end{array}$ & Yes; almost always & To a great extent & Reading-writing & Visual \\
\hline 2 & $\begin{array}{l}\text { Comfortable leaming English } \\
\text { individually as well as in a } \\
\text { group }\end{array}$ & $\begin{array}{l}\text { Yes; for pronunciation and } \\
\text { speaking mistakes }\end{array}$ & To a great extent & $\begin{array}{l}\text { Tactile/Kinesthetic } \\
\text { leamer - prefer to leam } \\
\text { via experience (moving } \\
\text { touching, doing) }\end{array}$ & Auditory \\
\hline 3 & $\begin{array}{l}\text { Comfortable leaming English } \\
\text { individually as well as in a } \\
\text { group }\end{array}$ & $\begin{array}{l}\text { Yes; feedback will help } \\
\text { correct the mistakes and } \\
\text { improve things overall }\end{array}$ & Somewhat & $\begin{array}{l}\text { Visual Leamer (is easier } \\
\text { to leam from pictures; } \\
\text { visual aids such as } \\
\text { overhead slides, } \\
\text { diagrams, handouts, etc.) }\end{array}$ & Visual \\
\hline 4 & $\begin{array}{l}\text { Comfortable leaming English } \\
\text { individually. }\end{array}$ & Not necessary & Somewhat & $\begin{array}{l}\text { Auditory leamer (best } \\
\text { leam through listening) }\end{array}$ & Auditory \\
\hline 5 & $\begin{array}{l}\text { Comfortable leaming English } \\
\text { individually. }\end{array}$ & $\begin{array}{l}\text { Yes; Prefer feedback from } \\
\text { instructor led activity or } \\
\text { from the application. }\end{array}$ & Not at all & $\begin{array}{l}\text { Visual leamer (is easier } \\
\text { to leam from pictures; } \\
\text { visual aids such as } \\
\text { overhead slides, } \\
\text { diagrams, handouts, etc.) }\end{array}$ & Reading/Writing \\
\hline
\end{tabular}

Fig14. Interaction / learning style

The above data is inconclusive (because of the limited design of the current study), but provides some preliminary indication about user interaction in this specific learning context.

\section{RECOMMENDATIONS FOR FUTURE APPLICATIONS}

We have had some interesting preliminary observations from the collected data and based on that, we can make some fairly generalized design recommendations.

\section{Interface-Based Recommendations}

1. Allow the interface to be intuitive enough, so that users of the application can skip steps and come back as and when they want to. Even when the activity is sequential, allow the interface to maintain a trail of activities as completed and attempted. This action might be reserved for the corner of the screen as an optional pop-up (Antoniou and Varadan, 2007).

2. Recent advances in touch screen technology have increased the prevalence of touch screens and have prompted a wave of new touch screen-based devices. Include accessibility features in the screen, where page size/text size could be zoomed-in directly on the touch screen through finger flexing (Ahmed et al., 2010).

3. Maintain a geometrical proportion between the numbers of text options shown for a matching task in an English exercise and how much of that text is visible on the screen without having to zoom-in. Adjust content accordingly. Objective results showed that there was little difference in reading performance above 6 point, but subjective comments from participants showed a preference for sizes in the middle range. We therefore suggest, for reading tasks, that designers of interfaces for mobile computers provide fonts in the range of 8-12 point to maximize readability for the widest range of users (Darroch et al., 2005).

4. Users do get frustrated with unresponsive systems. Even when a system closes down abruptly, the application should be programmed to include a "Restore Session" button. This recommendation is consistent with research findings suggesting that touch and multi-touch technologies have generated a great deal of excitement. Such research has focused on addressing the fundamental limitations associated with the use of touch as the primary input mechanism (Benko \& Wigdor, 2010).

5. New users of high-function application systems can become frustrated and confused by the errors they make in the early stages of learning. The language learning application must include user orientation sessions where novice users are given guidance on how to use the application on hand-held devices. Examples of short task completion should be provided. Creating a training environment from the basic function of the system itself can afford substantially faster learning coupled with better learning achievement and better performance (Carroll and Carrithers, 1984).

\section{Content-based Pedagogical Implications}

1. For any EFL context, the content should be simple. Research suggests that a mobile language course should definitely include survival phrases and dialogues in the form of games/crosswords/puzzles, listening and reading activities as well as the matching word activity and fill in the missing word activity. Research projects have stressed the critical importance of lower-order skills in the vocabulary acquisition of beginning level learners. Bottom-up 
processing, is an essential element of word knowledge that must be mastered before higher-order skills can be developed (Taraszow et al., 2010).

2. For MALL-based applications, readers preferred a more relaxing and flexible schedule where tasks were shorter and could be completed relatively easily without additional assistance. Content should be designed accordingly. Designers must know the difference between choosing content that might be a supplementary activity versus content that is a main activity (depending on the context of its use). Research suggests that for MALL-based language learning, readers prefer regular practice in short bursts (Traxler, 2007)

3. Readers might not be overwhelmingly in favor of group collaboration when completing MALL-based applications. This might be a result of the need for synchronous communication in group collaboration (KukulskaHulme \& Shield, 2008). It is possible for users to see MALL applications more as a way to upgrade their language skills individually, rather than learning from each other. So, it would be wise to compartmentalize the information and access accordingly. Allow users to switch between group and individual modes for the same content, but allowing different on-screen activities. The activities should allow for a choice between individual and group access. Content designers might want to strike a balance between the complexity of the content, the learning objectives in a learning module, its communication goals, and the extent to which group-based effort is warranted.

4.The way readers used the application in this study, it appears that extraordinary complexity in content and its design might not be well accepted and might indeed lead to user frustration, especially in an EFL context (although this viewpoint might be true for English as first language users too). Frustration might not be a result of users' language capability, but expectation about how they want to use a device. The extent to which a serious classroombased, graded assignment could be incorporated as part of MALL is still debatable and requires more research and for a wider context of use.

The recommendations here are consistent with what Donald Norman (1988) suggested about ensuring a high degree of visibility, providing adequate feedback, presenting a good conceptual model, and offering good mapping to make sense of any product design and its purpose.

\section{CONCLUSION}

The optimal combination of content, complexity, and interface design is still a challenge that needs to be researched more intricately and even more so in an EFL context with moderate levels of language proficiency. In Japan, the results have shown some success in this specific context with computer science majors in this study, but a lot more testing is needed before any conclusive remarks can be made. This study was a small-scale one with a focus group and designed to initiate a model for testing both content and application interface further. It also was designed to raise awareness of issues that need suitable and additional consideration. The combination of current $3 \mathrm{G}$ services and latest handset devices capabilities shows that technologically it is possible to overcome most of the MALL challenges. Nevertheless, the key for MALL success is to create activities based on clearly stated pedagogical approaches that suit and take advantage of the full technical possibilities of $3 \mathrm{G}$ and learning needs.

\section{REFERENCES}

[1] Antoniou, Z., Varadan. S. (2007). Intuitive Mobile User Interaction in Smart Spaces via NFC-Enhanced Devices, icwmc, pp.86, Third International Conference on Wireless and Mobile Communications.

[2] Apple Developer. IPhone Human Interface $\quad$ Guidelines. http://developer.apple.com/library/ios/\#documentation/UserExperience/Conceptual/MobileHIG/Introduction/Introduction.htm 1\#//apple_ref/doc/uid/TP40006556-CH1-SW1. Accessed 30th June 2011.

[3] Asbury, J. (1995). Overview of focus group research. Qualitative Health Research. 5(4). 414-420.

[4] Attewell, J., \& Webster, T. (2004). Engaging and supporting mobile learners. In Proceedings of MLEARNING 2004: Mobile learning anytime everywhere (pp. 15-20). London, UK: Learning and Skills Development Agency.

[5] Benko, H., \& Wigdor, D. (2010). Imprecision, Inaccuracy and Frustration: The Tale of Touch Input. Human-Computer Interaction Series, 2010, Part 2, 249-275, DOI: 10.1007/978-1-84996-113-4_11.

[6] Brusilovsky, P., (2001), "Adaptive Hypermedia", User Modeling and User-Adapted Interaction Journal, Vol. 11 No. 1-2, pp. 87-110.

[7] Carroll, J.M. (2000). Five reasons for scenario-based design. Interacting with Computers. 13 (1): 43-60.

[8] Carroll, J. M., \& Carrithers, C. (August, 1984). Training Wheels in a User Interface. Communications of the ACM Magazine. Volume 27, Issue 8, pp. $800-806$.

[9] Catterall, M \& Maclaran, P. (1997). Focus group data and qualitative analysis programs: Coding the moving picture as well as the snapshots, Sociological Research Online, vol 2, no. 1, pp. U53-U61.

[10] Cha, H. J., Kim, Y. S., Park, S. H., Yoon, T. B., Jung, Y. M., Lee J. H. (2006a): Learning styles diagnosis based on user interface behaviors for the customization of learning interfaces in an intelligent tutoring system. In Proc. ITS 06. LNCS 4053, Springer, 5135524.

[11] Chinnery, G. (2006). Emerging Technologies - Going to the MALL: Mobile Assisted Language Learning. Language Learning \& Technology, 10(1), 9-16. Retrieved November 30, 2006. http://ltt.msu.edu/vol10num1/emerging/default.html. 
[12] Darroch. I, Goodman, J., Brewster, S., \& Gray. P (2005). The Effect of Age and Font Size on Reading Text on Handheld Computers. Lecture Notes in Computer Science, Volume 3585/2005, 253-266, DOI: 10.1007/11555261_23.

[13] Dean, K. (2004). Duke gives iPods to freshmen. Accessed July 13, 2009 at http://www.wired.com/entertainment/music/news/2004/07/64282

[14] Ahmed. F, Muhammad A. I, Yevgen B, Ramakrishnan, I. V. (2010). Assistive web browsing with touch interfaces, Proceedings of the 12th international ACM SIGACCESS conference on Computers and accessibility, October 25-27, Orlando, Florida, USA.

[15] Fotouhi-Ghazvini, F., Earnshaw, R.A., and Haji-Esmaeili, L. (September, 2009). Mobile Assisted Language Learning in a Developing Country Context, CyberWorlds. CW '09 International Conference, vol., no., pp.391-397, 7-11.

[16] Gorienko, L. and Merrick, R (2003). No wires attached: Usability challenges in the connected mobile world, IBM System Journal, 42, 4, 639-651.

[17] Hackos, J. T and Redish, J. C. (1998). User and task analysis for Interface design. John Wiley \& Sons, Inc, New York.

[18] Horton, W. (2000). Designing Web-Based Training, (pp. 19-54). John Wiley \& Sons, Inc, New York.

[19] Houser, C. \& Thornton, P. (2005). Poodle: A course-management system for mobile phones. In H. Ogata, M. Sharples, Kinshuk, \& Y. Yano (Eds.), Proceedings of the third IEEE International Workshop, November 28-30, 2005, Los Alamitos, California: IEEE Computer Society, pp. 211-215.

[20] Klopfer, E., Squire, K., \& Jenkins, H. (2002). Environment detectives: PDAs as a window into a virtual simulated world. Proceedings of IEEE International Workshop on Wireless and Mobile Technologies in Education. Vaxjo, Sweden: IEEE Computer Society, 95-98.

[21] Kiernan, P. J., and Aizawa, KAZUMI. (2004). Cell phones in task based learning - Are cell phones useful language learning tools? ReCALL, 16, pp 71-84.

[22] Kukulska-Hulme, A. (2009). Will mobile learning change language learning? In ReCALL 21, 2. United Kingdom. P 157-165.

[23] Kukulska-Hulme, A. \& Traxler, J. (eds.) (2005). Mobile learning. A handbook for educators and trainers. Open and flexible learning series, Routledge, London.

[24] Kukulska-Hulme, A., and Shield, L. (2008). An Overview of Mobile Assisted Language Learning: Can mobile devices support collaborative practice in speaking and listening. ReCALL 20, 3 (Sep. 2008), 271-289. DOI: http://dx.doi.org/10.1017/S0958344008000335.

[25] Lan, Y., Sung, Y., \& Chang, K. (2007). A Mobile-Device-Supported Peer-Assisted Learning System for Collaborative Early EFL Reading. Language Learning and Technology. Vol. 11, No. 3, pp. 130-151.

[26] Marco Winckler, Hilary Johnson, Philippe A. Palanque (Eds.): Task Models and Diagrams for User Interface Design, 6th International Workshop, TAMODIA 2007, Toulouse, France, November 7-9, 2007, Proceedings. Lecture Notes in Computer Science 4849 Springer 2007, ISBN 978-3-540-77221-7.

[27] Morita, M. (2003). The Mobile Based Learning (MLB) in Japan. Proceedings of the first conference on creating, connecting and collaborating through computing.

[28] Naismith, L., Lonsdale, P., Vavoula, G. \& Sharples, M. (2004). Literature Review in Mobile Technologies and Learning. FutureLab Report 11. Accessed 27th August 2007 from: http://www.futurelab.org.uk/resources/documents/lit_reviews/Mobile_Review.pdf

[29] Nielson, J and Molich, R. (1990). Heuristic evaluation of user interfaces. Proceedings of the SIGCHI Conference on Human Factors in computing systems: empowering people. DOI: 10.1145/97243-97281.

[30] Norman, D. A. (1988). The Psychology of Everyday Things. Basic Books.

[31] Paredes P. \& Rodriguez P. (2002). Considering learning styles in adaptive web-based system. In Proceeding of the 6th World Multiconference on Systemics, Cybernetics and informatics (eds N. Callaos, M. Margenstern \& B. Sanchez), pp. 481-485. Orlando, FL.

[32] Read, B. (2005). Seriously, iPods are educational. Chronicle of Higher Education, 51(28), A30-A32.

[33] Ruth, S. (2010). Is E-Learning Really Working? The Trillion-Dollar Question. In IEEE Internet Computing, vol. 14, no. 2, pp. 78-82, Mar. /Apr.

[34] Shneiderman, B., Plaisant, C. (March 2009). Designing the User Interface: Strategies for Effective Human-Computer Interaction: Fifth Edition. Addison-Wesley Publ. Co., Reading, MA.

[35] Soloway, E., Norris, C., Blumenfeld, P., Fishman, B., Krajcik, J., \& Marx, R. (2001). Log on education: Handheld devices are ready-at-hand. Communications of the ACM, 44(6), 15-20.

[36] Sommerville, I. (1995). Software Engineering. Addison-Wesley, $5^{\text {th }}$ edition. US, pp. 319-343.

[37] Song, J. (2008). Mobile Learning: What is going on? International Symposium on Knowledge Acquisition and Modeling, 2008. KAM '08. (Pp.411-414), 21-22 Dec.

[38] Tarasewich, P; Gong, J; and Nah, F (2007). Interface Design for Handheld Mobile Devices. AMCIS 2007 Proceedings. Paper 352. http://aisel.aisnet.org/amcis2007/352

[39] Taraszow. T., Aristodemou. E., Slavidou, V., Burston, J., and Laouris, Y. (2010). Proceedings of the Social Applications for Lifelong Learning Conference, Patra, Greece, 4-5 November.

[40] Thornton, P. and Houser, C. (2004). Using Mobile Phones in Education. In Proceedings of the 2nd IEEE International Workshop on Wireless and Mobile Technologies in Education. pp. 3- 10.

[41] Traxler, J. (2007). Defining, discussing, and evaluating mobile learning: The moving finger writes and having writ..., International Review of Research in Open and Distance Learning, vol. 8, no. 2, pp. 1-12.

[42] Wolf, C. (2002): iWeaver: Towards an Interactive Web5Based Adaptive Learning Environment to Address Individual Learning Styles. In Proc. ICL. 
Ruth Patricia Cortez is a PhD student of Computer Science at the University of Aizu. Her research interests are in mobileassisted language learning processes, interface design, Semantic Web, and Service Oriented Architecture. She is actively involved in research on these fields and has published papers in International Conferences. She earned her M.S. from the University of Aizu and has previous industry experience. The focus of her research is on developing a platform for e-Learning services integration.

Debopriyo Roy is an Associate Professor of Technical Communication and Usability at the University of Aizu, Japan and also the director of the Technical Communication Laboratory there. He holds MA degrees in Economics and Communication Arts and a $\mathrm{PhD}$ in Communication and Rhetoric from RPI, NY. He specializes in information design, usability studies, technical writing, and web-based training. His research focuses on information design and usability. He has published extensively in international journals and has refereed conference proceedings. He served as the vicechair of the IEEE Japan Chapter on Professional Communication and is a member of IEEE PCS. He was also the chair of the ACM Chapter on E-learning and Technical Communication. 